\title{
Author Correction: T-bet-dependent NKp46+ innate lymphoid cells regulate the onset of $T_{H}$ 17-induced neuroinflammation
}

Brandon Kwong (D), Rejane Rua, Yuanyuan Gao, John Flickinger Jr, Yan Wang, Michael J Kruhlak, Jinfang Zhu,

Eric Vivier (D), Dorian B McGavern and Vanja Lazarevic (D)

Correction to: Nature Immunology https://doi.org/10.1038/ni.3816 (2017); published online 14 August 2017.

In the version of this article initially published, in second paragraph of the second subsection of Results ('Peripheral licensing of CD4 ${ }^{+}$ $\mathrm{T}_{\mathrm{H}} 17$ cells in $\mathrm{Tb} \times 21^{-/-}$hosts'), the figure citation ('Fig. 1c') in the sentence that begins "In addition to" was incorrect. The correct citation is 'Fig. 1d'.

Published online: 29 June 2018

https://doi.org/10.1038/s41590-018-0139-6

\section{Publisher Correction: Macrophages: damage control}

\section{Zoltan Fehervari}

Correction to: Nature Immunology https://doi.org/10.1038/s41590-017-0040-8; published online 18 January 2018.

In the version of this Research Highlight initially published, the url for the linked article was incorrect (https://doi.org/10.1172/ JCI90647JCI90647). The correct link is https://doi.org/10.1172/JCI90647. The error has been corrected in the HTML and PDF versions of the article. 